\begin{tabular}{|c|c|}
\hline Revista de Filosofia & $\begin{array}{l}\text { AUFKLÄRUNG, João Pessoa, v.3, n.2, Jul-Dez., 2016, p.101-112 } \\
\text { DOI: http://dx.doi.org/10.18012/arf.2016.30417 } \\
\text { Recebido: } 29 / 08 / 2016 \mid \text { Aceito: } 18 / 09 / 2016 \\
\text { Licença: Creative Commons 4.0 International (CC BY 4.0) }\end{array}$ \\
\hline
\end{tabular}

\title{
CONSCIÊNCIA SOCIAL, COMUNIDADE ÉTICA E CRÍTICA DA ALIENAÇÃO EM HABERMAS
}

\author{
[MORAL CONSCIOUSNESS, ETHICAL COMMUNITY AND THE CRITICS OF THE ALLIENATION IN \\ HABERMAS]
}

Marcos Alexandre Alves *

Paloma Lencina Mello **

\begin{abstract}
Resumo: O estudo aqui desenvolvido trata da formação da consciência social tensionada pela alienação e emancipação intersubjetiva. $\mathrm{O}$ problema da pesquisa é saber como o agir comunicativo de Habermas pode contribuir para a formação da consciência social/ética, contraposta aos processos de alienação. Para tanto, será feito uma releitura históricoconceitual de alguns pontos da filosofia habermasiana. Objetiva-se, assim, discutir quais os principais elementos da Teoria do Agir Comunicativo contribuem para a formação de uma consciência social que concilie comunidade e pluralidade. Os sujeitos inevitavelmente fazem parte de certos contextos. Participar de um contexto/comunidade, exige uma consciência social atravessando as relações, o que implica co-responsabilidade e cooperação. Por fim, a formação de uma consciência sócio-ética só é possível através de uma comunicação aberta e argumentativa, cuja normatividade traz uma pretensão de validade pública.
\end{abstract}

Palavras-chave: Agir Comunicativo. Formação da Consciência Social. Ética Discursiva. Comunidade plural.
ABSTRaCT: The study developed here deals with the formation of social consciousness tensioned by inter-subjective alienation and emancipation. The research problem is how the communicative action of Habermas can contribute to the formation of socio-ethical consciousness, as opposed to divestment/alienation processes. To do so, it will be a historical-conceptual rereading of some points of Habermas's philosophy. It aims as well to discuss what the key elements of Communicative Action's Theory contribute to the formation of a social consciousness which reconciles community and plurality. The subject inevitably belong to certain contexts. To participate in a context/community, it requires a social conscience through relationships, which implies co-responsibility and cooperation. Finally, the formation of a socio-ethical awareness is only possible through an open and argumentative communication, it brings a normative framework for a public claim of validity.

KEYwORDS: Communicative Action. Formation of Social Consciousness. Discourse ethics. Pluralistic community.

* Doutor em Educação pelo Programa de Pós-Graduação em Educação da Universidade Federal de Pelotas. Mestre em filosofia. Coordenador do Curso de Filosofia e Professor Adjunto do Curso de Filosofia, do Programa de Pós-graduação em Ensino de Ciência e Matemática, e do Programa de Pós-Graduação em Ensino de Humanidades e Linguagens - Centro Universitário Franciscano. m@ilto: maralexalves@gmail.com. ** Centro Universitário Franciscano. m@ilto: palomamelo@gmail.com. 


\section{INTRODUÇ̃̃o}

$\mathrm{O}$ presente texto tem como tema a formação da consciência social (e moral) atravessada pela tensão entre alienação e emancipação (inter) subjetivas. $\mathrm{O}$ tema será desenvolvido a partir da teoria do agir comunicativo do filósofo alemão 102 Jürgen Habermas (1929 -). Isto se dará no cruzamento da hermenêutica crítica e do pragmatismo transcendental da geração tardia da Escola de Frankfurt, que convergirá, em parte, na chamada, Ética do Discurso. Habermas encontra-se filiado a Escola de $\approx \quad$ Frankfurt que recepciona duas grandes tradições. Uma das tradições é a Iluminista, representada por Kant, e a outra, é representada por autores pós-hegelianos, tais como Marx (reinterpretado no interior da teoria crítica).

O nosso problema, concretamente, assim se apresenta: como pode o agir comunicativo contribuir para a formação da consciência social (e moral) sendo que há tantos processos de alienação na sociedade?

A partir do problema delineado, tem-se como objetivo geral discutir quais os principais elementos da teoria do agir comunicativo contribui para a construção de uma consciência social. Além disso, procura-se delinear o que Habermas entende por agir comunicativo; analisando os temas da alienação e ideologia partindo da apropriação habermasiana de Marx. Dessa forma, busca-se diferenciar agir estratégico/instrumental (relações de poder, discurso ideológico, alienação) e agir comunicativo; distinguir os conceitos de mundo da vida e sistema e avaliando suas implicações na compreensão das relações sociais complexas, e por fim, mostrar qual o tipo de racionalidade deve preceder, para e a partir de Habermas, uma consciência social (reconhecendo os pressupostos lógicos e morais do discurso socializante) que instaure um senso ético de coletividade e crítica permanente das ideologias.

A pesquisa desenvolvida conta com uma metodologia de análise e interpretação de textos. Será feita uma investigação problemática ligada ao tema citado. Análise histórico-conceitual e hermenêutica com foco autoral. Como fundamentação teórica principal conta-se com as obras do próprio Habermas, como exemplo, Teoria do agir comunicativo (2012) e Comentários à ética do discurso (1991). Serão utilizados também obras secundárias, tais como, Habermas e a educação: ação pedagógica como agir comunicativo (MUHL, 2003), contando ainda, com o eventual uso de artigos que darão suporte para a compreensão da teoria de Habermas.

\section{O Discurso Filosófico da Modernidade}

Uma chave teórica fundamental da assim chamada Ética do Discurso (Habermas) é a distinção entre agir instrumental e agir comunicativo, e o papel da comunicação na constituição de uma comunidade ética, via consenso crítico.

No espírito da dialética negativa (crítica feita por autores pertencentes a Escola de Frankfurt em relação ao sistema capitalista-desconstrução de ideologias feitas desde Adorno à Habermas) e da crítica genealógica (inspiradas em Nietzsche, Marx e Freud) a linhagem frankfurtiana vem denunciar os processos de alienação/totalização. Dessa forma, busca-se sondar as possibilidades remanescentes num mundo pós-guerras, de um processo de emancipação e cooperação racional dos sujeitos livres.

$\mathrm{O}$ olhar habermasiano vai, de forma menos crítico-negativa e mais procedimental-propositiva, apontar que toda enunciação porta consigo um modo de ação e este agir implica, para validar-se, uma comunicação intersubjetiva. Uma exigência normativa uniria sujeitos, através da comunicação, em suas pretensões de validade.

Habermas pretende reestabelecer e atualizar, de forma crítica, o projeto do iluminismo de emancipação dos sujeitos; porém, não mais pela via da razão subjetivista do indivíduo auto-pensante, mas pelo caminho da razão intersubjetiva (sentido construído pelas relações entre os sujeitos). A razão subjetiva, todavia, encontra-se 
atravessada pela e exercitada na comunicação, no reconhecimento das condições e fins de uma comunidade, ao mesmo tempo, possível e pressuposta.

Ao fazer uma releitura filosófica da modernidade, Habermas a define com um projeto inacabado e como um processo que se move por si mesma, se automatizando conforme evolui. Decerto, é preciso fazer a crítica da modernidade, não no sentido de sua negação, mas de sua compreensão e reapropriação lúcida.

A modernidade parece estar ligada a uma consciência de tempo/época (zeitgeist) que possui uma necessidade de autocertificação (HABERMAS, 2000). Desde Hegel, passando pelos idealistas românticos, os hegelianos de esquerda e direita, Marx, Nietzsche, Heidegger, passando pelos frankfurtianos, até Derrida e Foucault, a noção de modernidade sofre transformações diversas. Habermas percorre essas etapas, analisando-as, para propor, na esteira da descentralização da filosofia do sujeito, uma noção de razão comunicativa que mantém o conteúdo normativo da modernidade.

Habermas (2000) entende que a autocertificação da modernidade é o problema fundamental de Hegel. O fundamento da modernidade, para Hegel, reside na noção de subjetividade, comportando quatro conotações: a) Individualismo - singularidade em busca de validade; b) Direito de crítica - aquilo que deve ser reconhecido por todos deve se mostrar a cada um como algo legítimo; c) Autonomia da ação - poder de decidir implicando responder pelos atos; d) Idealismo - primado da autoconsciência, onde a filosofia apreende a ideia de que se sabe a si mesma.

Contudo, presa do idealismo, Hegel não resolveu, dentro do otimismo de uma dialética do esclarecimento, enquanto sistema, o problema que soube enunciar por meio das noções de processo, de história e de razão. Neste sentido, foram os hegelianos de esquerda e os pós-hegelianos, tais como Marx, que confrontaram as pretensões da razão idealista e propuseram críticas estruturais, sejam de tipo materialista seja de tipo existencialista (HABERMAS, 2000). Marx, particularmente, desloca o foco do modelo da autorreflexão egológica para a práxis como ação produtiva que implica e/ou engendra consciência social. Além disso, estabelece uma crítica das ideologias e uma análise dos processos de alienação ou de fragmentação da ação/consciência. Portanto, segundo Habermas, entender a modernidade é compreender um processo do qual todos ainda somos tributários e participantes.

Há, ainda, uma necessidade crescente de se repensar o humano enquanto participante de uma sociedade. O humano que faz parte de um contexto no qual deve se engajar no sentido da comunidade, mas, também se individuar mantendo sua personalidade. Desse modo, faz-se necessário perguntar-se sobre o que implica fazer parte de um grupo, ser integrante de uma sociedade com valores morais e éticos constituídos, mas em cuja tensão interna - conflitos de interesses, choque de ideologias - a construção de um consenso mínimo e cooperação básica se torna crucial.

Habermas não nega a modernidade, nem se prende a limites empiristas ou idealistas. Ele procura reavaliar e revisitar a mesma. Por isso, retoma o iluminismo no sentido de acreditar no poder de emancipação dos sujeitos através da razão. Retoma a teoria crítica para denunciar os processos de alienação e ideologias. Essa retomada acontece de forma crítica. O filósofo se dá conta que o iluminismo aposta demais em um progresso científico e em uma racionalidade que ordena tudo. Nesse sentido, Habermas detecta algumas limitações do ideal de racionalidade iluminista.

Ao mesmo tempo em que ocorre o crescimento das lutas para a universalização dos direitos individuais e coletivos em relação às conquistas científicas, crescem as denúncias que revelam a crescente manipulação tanto ideológica quanto biológica do ser humano pela ciência. Assim, ao invés de fortalecer o indivíduo diante da natureza e diante da sociedade, a ciência tem-no tornado cada vez mais impotente e dependente, a ciência, que surgiu na modernidade como principal recurso de libertação da espécie humana, torna-se o seu principal meio de dominação. O preço que a humanidade precisa pagar pela extensão do poder científico sobre a natureza e a sociedade é a impotência do indivíduo, 
concretizada historicamente frente as instituições e frente a sua própria existência (MÜHL, 2003, p. 26).

As ideologias e os processos de alienação surgem de uma razão manipuladora e utilitarista. Os limites da razão moderna existem ao passo que, os avanços científicos e tecnológicos, por exemplo, atuam na vida dos sujeitos de modo negativo e não só positivo.

Nas relações cotidianas percebe-se a razão instrumental e a razão comunicativa agindo juntas. Quando um grupo de pessoas pertencentes a uma associação comunitária se reúnem para decidir o que fazer com o dinheiro do caixa, ali está presente a razão instrumental e razão comunicativa. A razão instrumental é aquela que permite os sujeitos decidirem o fim útil do dinheiro, por exemplo, enquanto o diálogo visando um consenso diz respeito à razão comunicativa. Assim, sem a razão comunicativa não conseguimos ultrapassar os egocentrismos da razão instrumental. Ultrapassando o monólogo do sujeito solitário é possível, por um diálogo racional ampliado, estabelecer uma comunidade ética racional.

Razão instrumental e os pressupostos lógicos e éticos do discurso

Vivemos uma época em que a técnica e a estratégia crescem em importância numa sociedade cada vez mais complexa e, ao mesmo tempo, automatizada e burocratizada. $\mathrm{O}$ avanço tecnológico aumentou a produção e o consumo, numa sociedade de massas onde a propaganda tem força. Mas o século XX foi palco de horrores que denunciam os riscos de uma instrumentalização da razão e de uma descaracterização das relações humanas.

Quando a razão instrumental, aliada a uma ideologia totalitária, solapa a razão comunicativa, tem-se fenômenos tais como os regimes concentracionários e genocídios, dos quais o holocausto (shoah) é o exemplo paradigmático. Nele a técnica e a estratégia forma unidas no extermínio humano sistemático.

Habermas (2012) assumiu, portanto, a necessidade de uma crítica da razão instrumental exacerbada como reificação/coisificação do humano. Isso passa pela crítica da ideologia, da alienação, da massificação (p.637) e da mera reprodução sistêmica.

Os pressupostos lógicos e morais de qualquer consenso possível ou comunidade construtível devem ser enunciados. Uma consciência social emerge do entrelaçamento dos valores éticos, que dizem respeito às decisões e relações diárias, e dos desafios de coordenação de interesses na direção de graus crescentes de consenso. Mas existem alguns processos de alienação muito pertinentes que desafiam o consenso racional e se chocam com os processos de emancipação, pelos quais todo consenso se tornaria legitimado publicamente. A emancipação acontece através do exercício das liberdades que, mantendo sua autonomia, entram em relação deliberativa visando um acordo consensual que sustente as liberdades totais da comunidade.

A autonomia da reflexão e da deliberação, implicando autoanálise e autocrítica, conforme observa Habermas (2007b), é apenas um dos requisitos do discurso prático. $\mathrm{O}$ outro, igualmente importante, é que os participantes, no momento em que iniciam a prática argumentativa, devem estar dispostos a atender à exigência de cooperar uns com os outros na busca por razões aceitáveis para os outros, e estarem dispostos a deixar-se afetar e motivar por razões publicamente aceitáveis. Assim, os pressupostos pragmáticos da discussão/discurso mostram que ambas as condições podem ser satisfeitas: a) cada participante individual livre deve ter autoridade epistêmica para dizer "sim" ou "não"; b) deve haver uma busca de um acordo racional, segundo um consenso crítico que implique a todos os envolvidos e afetáveis. Segundo Habermas, isto estabelece, pela implicação de comunidade na comunicação, um "sublime vínculo social": "uma vez que encetamos uma práxis argumentativa, deixamo-nos enredar, por assim dizer, num vínculo social que se preserva entre os participantes mesmo quando eles se dividem na competição pela busca do melhor argumento" (2007b, p.16).

Essa práxis argumentativa implica a racionalidade comunicativa, revelando o 
fundo intersubjetivo de toda consciência social. Contudo, ao se estabelecerem, os "vínculos" podem ser ameaçados pela exacerbação ou perda de uma das condições: pessoalidade e publicidade. Quanto mais nos debruçarmos sobre tal problemática buscando compreendê-la em profundidade e amplitude, melhor se poderá coordenar as ações concretas e os discursos para conceber e realizar projetos comuns. $\mathrm{O}$ discurso implica a partilha de razões comuns que não se dão apenas no plano teórico, mas se articulam no plano prático da coordenação de ações num espaço público.

\section{A TEORIA CRÍTICA E A NOÇÃo dE AGIR COMUNICATIVO FRENTE À REALIDADE CONTEMPORÂNEA}

Habermas é um filósofo herdeiro de tradições filosóficas diversas: pragmática, porque refere de um contexto de interações prático-linguísticas; transcendental, pois enfatiza as condições de possibilidades do discurso; hermenêutica, na medida em que leva em conta a interpretação de contextos, compreendendo os sentidos enunciados como razões ativas nas relações intersubjetivas; analítica, o que implica análise do discurso em sua estrutura de enunciação. Tais tradições foram recombinadas sob o prisma da teoria crítico-social da assim chamada Escola de Frankfurt, que floresceu durante e imediatamente após a Segunda Guerra Mundial.

A Escola de Frankfurt, cujas bases foram lançadas por Adorno e Horkheimer, e em cuja alçada nomes tais como Marcuse, Benjamin e Fromm se reuniram, combinou filosofia com estudos sociais, políticos, históricos e psicológicos. As influências de Hegel, Nietzsche, Marx, Freud e Kant se fizeram sentir em sua "teoria crítica", combinando uma "dialética negativa" com uma permanente tomada de consciência dos mecanismos de alienação e de (possível) emancipação no mundo moderno Pósindustrial.

A lógica profunda, e o pressuposto moral, de toda comunicação implicaria a compreensão mútua, a sinceridade das expressões e a pretensão de validade (com reconhecimento mútuo da verdade das proposições pela comunidade dos envolvidos). A teoria habermasiana tentará escavar tais pressupostos e com eles enunciar procedimentos legítimos. A noção de agir comunicativo é essencial para tal, posto que é definido como um modo de ação em que as razões são tornadas públicas e cuja orientação é o consenso através da comunicação, discussão e argumentação.

Para Habermas (2012a), na esteira da teoria marxista relida pela ótica frankfurtiana, critica os processos de alienação e as ideologias presentes na vida contemporânea e defende uma consciência social constituída (segundo os pressupostos lógico-morais que operam sob a comunicação) pelo discurso público aberto, coordenando validade (norma pública) e responsabilidade (autoria/posição pessoal).

Sendo o humano portador de uma linguagem nada mais inteligente que fazer uso dela em seu benefício (no caso da comunicação de suas necessidades) e também em benefício da comunidade (por meio da interação social). É somente por meio do diálogo argumentativo que os sujeitos podem chegar a um consenso crítico e a uma universalidade, ideais esses que são parte importante da teoria do agir comunicativo. Nas palavras de Habermas, "a linguagem preenche três funções, uma delas é- a função da integração social ou da coordenação dos planos de diferentes atores na interação social" (2003, p. 41). A intenção fundamental da linguagem é a compreensão mútua, portanto, toda comunicação opera no sentido da comunidade.

A fim de tratar a importância do agir comunicativo na vida prática dos sujeitos, exemplificamos o uso da teoria da seguinte maneira: é somente através de um diálogo argumentativo que é possível escolher um buffet de uma festa ou chegar a um acordo sobre questões educacionais e políticas de uma sociedade. Nesse sentido, a teoria do agir comunicativo se faz importante porque ela diz de uma tomada de consciência por parte do sujeito diante da razão instrumental, razão essa que não é comunicativa e sim opressora e dogmática. 
A racionalidade instrumental, articulada com a técnica e realizada pelo agir estratégico, essa que não permite o diálogo e não está disposta a um consenso, posto "esconde os motivos" e "manipula as circunstâncias" segundo fins egocêntricos ou meramente utilitários. Nesse sentido, para Habermas (2012b), uma vez que o sujeito se compromete no diálogo ele também está se comprometendo com a sua ação, ou seja, o seu agir autônomo se vê implicado numa validação intersubjetiva. $\mathrm{O}$ agir comunicativo, por sua vez, tem como princípio a autonomia, a racionalidade, a verdade e a universalidade. Nesse ponto, cabe dizer que a noção de universalidade na teoria de Habermas tem como fundamento o imperativo categórico de Kant (toda ação para ser moral deve ser realizada por dever, isto é, sem nenhuma intenção que não o dever de fazer a coisa certa. Somente uma ação por dever pode ser universalizada). O Princípio de universalização é reconstruído por Habermas (2007b, p.8) em termos discursivos e passa a servir como regra da argumentação ideal. A citação a seguir esclarece o sentido de ideal do consenso universal:

A estratégia do discurso ético revela-se promissora, uma vez que o discurso oferece precisamente uma forma de comunicação mais exigente e que transcende as formas concretas de vida, pela qual as pressuposições da ação orientada para a comunicação são generalizadas, abstraídas e ampliadas, no sentido do seu alargamento a uma comunidade de comunicação ideal e inclusiva de todos os sujeitos dotados de capacidade de linguagem e ação (HABERMAS, 1991, p. 21).

Discutir a teoria do agir comunicativo, atualmente, faz-se não só importante como necessário, justamente quando propõe uma interação dialógica e comprometida entre os sujeitos. Interação que permite o autoconhecimento e a afirmação da própria identidade pois "o indivíduo só consegue sua identidade como pessoa graças à identificação com características da identidade coletiva ou graças à internalização dessas características" (HABERMAS, 2012b, p. 108).

A participação do sujeito nas discussões e problemas da sua sociedade é o que permite a ele reconhecer-se enquanto pessoa. Uma vez que o sujeito conhece, por exemplo, as reivindicações de vizinhos da sua comunidade, consegue ver-se refletido nas aflições dos outros, passa a ter um senso de coletividade. Nesse sentido, "o pluralismo exige simultaneamente a adoção de um ponto de vista moral e um acordo político razoável em relação à justificação dos princípios que organizam as instituições básicas da sociedade democrática" (MELO, 2011b, p. 20).

Nessa perspectiva, para Habermas (2007a), o reconhecimento de si se dá através da interação. O outro é importante para o desenvolvimento do eu, isto é, a individuação passa pela socialização tanto quanto a norma comunitária implica a pluralidade de vozes participando da ação comunicativa.

\section{ÉTICA DO DISCURSO E A DIFERENÇA ENTRE AGIR ESTRATÉGICO E AGIR COMUNICATIVO}

A ética do discurso desenvolvida por Habermas está fundamentada na teoria do agir comunicativo, que visa um consenso através do diálogo argumentativo, que pressupõe verdade e normatividade. O consenso deve "ser consequência da fundamentação e não critério de fundamentação" (DUTRA, 2002, p. 140). Consequência da fundamentação porque tem implicado uma ética discursiva. A citação a seguir apresenta qual é a fundamentação da ética do discurso:

O ponto de partida é a teoria do agir comunicativo, a troca de atos de fala vem calcada na pretensão de que haja verdade, normatividade e sinceridade. A ética assume uma teoria especial da argumentação, pressupõe que acordos podem ser fundamentados, que experiências morais como sentimento de injustiça, indignação, reprovação, são suscetíveis de um juízo moral. Há uma rede prática 
de atitudes e decisões, que demandam a participação efetiva em atos comunicativos na vida cotidiana. A ética do discurso é cognitivista, quer dizer, a ação ética, em última análise depende de compreensão racional e de aceitação racional da validade de princípios, do dever ser universal, antes mesmo da pergunta pela vida boa e feliz (ARAÚJO, 2009, p. 273).

Para Habermas, todos os sujeitos podem participar do discurso e devem fazê-lo de modo consciente e livre. Isso porque, "o consenso universal pressupõe um contexto livre de violência e coação, em que todos os integrantes de um discurso possam participar em pé de igualdade" (HABERMAS, 1990, p. 24). O poder só é legítimo após o consenso entre os participantes, a saber, o poder não pode ser uma força externa sobre o discurso. Nas palavras de Habermas, "o discurso prático é um processo, não para a produção de normas justificadas, mas para o exame da validade de normas consideradas hipoteticamente" (2003, p. 148). A validade das normas é dada pelo discurso, momento esse de interação responsável que visa um consenso.

Habermas (2012b), ao tratar do agir estratégico usa como exemplo a relação das ideologias com o poder e os processos de alienação da sociedade. É Marx (1987) que inaugura a teoria da alienação tendo como pano de fundo uma análise econômicopolítica. O conceito de alienação, em Marx, tem vários desdobramentos. Habermas analisa, principalmente, o conceito marxista de alienação no sentido econômico, político e subjetivo. Ou seja, respectivamente, a cisão entre o autor e a obra, o cidadão e o poder, o sujeito e seu senso de identidade.

Alienação, para Marx, diz respeito à fragmentação das capacidades do humano, ao estranhamento do indivíduo para com suas atividades. Nesse sentido, a alienação implica "a inversão e confusão de todas as qualidades humanas e naturais, a irmanação das impossibilidades - a força divina - do dinheiro repousa na sua essência enquanto essência genérica, alienante e auto-alienante. O dinheiro é a capacidade alienada da humanidade" (MARX, 1987, p. 196).

Segundo Habermas (2012b), Marx fornece as bases para uma análise da colonização interna do mundo-da-vida pelo sistema, através da dupla função de uma teoria da reificação e uma teoria da consciência de classe, porém não desdobra isto no plano ético-discursivo. Habermas, por sua vez, usa do termo alienação em um sentido mais restrito, ou seja, em um sentido sócio-político. Na teoria de Habermas é alienado todo o sujeito que não participa da esfera pública de modo consciente. $\mathrm{O}$ ato produtivo será voltado, no contexto comunicacional, para a produção do consenso normativo mais do que na reprodução do sistema. A reprodução ideológica é alienante. A ética do discurso incorpora uma normatividade.

Existem a título de curiosidade, vários tipos de ideologias como, por exemplo: democrática, capitalista e conservadora. O que são ideologias? Ideologias são ideias que pertencem a um determinado grupo de pessoas que geralmente estão em uma posição social elevada e com isso espalham de forma dogmática, e não problematizadora, suas ideias políticas e/ou educacionais. Nesse sentido, é que Habermas faz uma relação entre ideologia e poder. As ideologias e o poder pertencem ao agir estratégico, por não permitirem um diálogo aberto e argumentativo dentro de um campo de igualdade entre os sujeitos.

A ideologia tecnocrática, segundo Habermas, é "muito mais indevassável que as do passado, porque ela está negando, na verdade, a própria estrutura da ação comunicativa, assimilando-a a ação instrumental" (1990, p. 16). Deste modo, a técnica acaba instrumentalizando toda ação, impedindo assim que a ação seja do tipo comunicativa, isto é, aberta para a argumentação e cooperação mútua entre os sujeitos.

Por conseguinte, de acordo com Habermas (1990), para melhor explicar a função da ideologia é possível compará-la com o processo da neurose freudiana, que impede a comunicação do sujeito com a sociedade. Da mesma forma acontece com as ideologias, elas acabam por impedir que assuntos importantes sejam discutidos racionalmente. A falta de problematização de tais assuntos passa a favorecer o sistema de poder. $\mathrm{O}$ ser 
alienado já não problematiza a realidade e isso favorece os discursos ideológicos e consequentemente o sistema de poder. Discursos políticos e religiosos, por exemplo, servem para manobrar e "aquietar" uma população consciente e comprometida com seus direitos em uma sociedade. Uma vez que os temas não são discutidos em público eles são transferidos para o inconsciente. Dessa maneira é que Habermas vê na terapia uma saída para que o sujeito volte a ter consciência dos temas e então possa reintegrálos em um discurso público. Portanto, a própria discursividade possui um papel terapêutico, curando a "neurose pública" ou alienação, desde que haja sinceridade e justificação atravessando os atos discursivos.

$\mathrm{O}$ agir comunicativo, no entanto, propõe uma discussão aberta, cooperativa e ética que conta com um tipo de racionalidade discursiva e não dogmática e que sempre "aponta" para um consenso. Enquanto os processos de alienação e a relação das ideologias com o poder contam com um tipo de racionalidade técnica. A técnica fecha o diálogo, posto que se baseia em reprodução padronizada, não possibilitando que o sujeito exerça toda sua liberdade através da argumentação. Nas palavras de Habermas, o agir comunicativo ou o agir estratégico tornam-se:

necessários se um actor puder executar seus planos de acção unicamente de um modo interactivo, isto é, com a ajuda da acção (ou inacção) de um outro actor. $\mathrm{O}$ agir comunicativo tem, além disso, de obedecer a determinadas condições de cooperação e de entendimento: a) os actores intervenientes comportam-se de um modo cooperativo e tentam coordenar os respectivos planos (no horizonte de mundo da vida partilhado) com base em interpretações comuns (ou suficientemente coincidentes) da respectiva situação ; b) os actores intervenientes estão dispostos a alcançar os fins mediatos, da definição comum da situação e da coordenação de acções, assumindo o papel de locutores e de ouvintes e através de processos de entendimento, ou seja, pela via do prosseguimento sem reservas ou sincero de fins ilocutórios (...) "O agir comunicativo distingue-se, portanto, do agir estratégico pelo facto de uma coordenação da acção bem sucedida não se dever à racionalidade orientada para fins, própria das orientações da acção, mas, sim, à força racionalmente motivadora de realização de entendimento, isto é, a uma racionalidade que se manifesta nas condições de um consenso alcançado pela comunicação (HABERMAS, 2004, p.136-37).

\section{E acrescenta}

Abordei o agir comunicativo e o agir estratégico como duas variantes da interação mediada pela linguagem. Contudo, só ao agir comunicativo se aplica que as limitações estruturais de uma linguagem partilhada a nível intersubjetivo levam os atores - no sentido de uma necessidade transcendental débil - abandonarem o egocentrismo de uma orientação pautada pelo fim racional do êxito próprio e a submeterem-se aos critérios públicos da racionalidade do entendimento (HABERMAS, 2004, p. 94-95).

\section{MUNDO DA VIDA E SISTEMA: INTERFERÊNCIA NA VIDA HUMANA}

Habermas para explicar os problemas da modernidade apresenta duas categorias: mundo da vida e sistema. $\mathrm{O}$ mundo da vida refere-se às relações espontâneas entre os sujeitos, as experiências diárias, ao dinamismo das relações, isto é, as diferenças existentes nas relações, seja diferença cultural, econômica ou social. O ponto é que o agir comunicativo respeita toda essa pluralidade do mundo da vida. Se, por um lado, o mundo da vida abarca os mais diferentes modos de existir, o sistema, por sua vez, diz de uma razão instrumental com discursos prontos e ideológicos, que não respeita as diferenças, mas sim, busca dominar o sujeito. Na sequência, a citação apresenta qual é uma das implicações do caráter de dominação do sistema na vida cotidiana dos humanos, tendo 
como exemplo de ideologias a técnica e a ciência:

A força ideológica da técnica e da ciência centra-se no seu poder prático de promover o desenvolvimento econômico e de incrementar os níveis de consumo da população, elas se apresentam como variáveis independentes, fundamentais, das quais dependem a manutenção e a ampliação do poder produtivo e consumidor, propagam a ideia de que a estabilidade e o desenvolvimento econômico e sociocultural dependem de uma adequada estrutura administrativa e da intervenção competente de tecnocratas. A população, consequentemente, passa a acreditar que sua felicidade e seu bem-estar dependem do desenvolvimento técnico-científico, os interesses sociais passam a coincidir, dessa forma, com os interesses sistêmicos (MUHL, 2003, p. 97).

Nessa perspectiva, a técnica e a ciência juntas formam uma pseudo-legitimação no que diz respeito as verdadeiras necessidades de uma população. $O$ agir comunicativo, no entanto, por dizer de uma interação cooperativa entre os sujeitos, contribui para que os mesmos não se deixem enganar por essa rede de alienação. Os interesses que dizem respeito à vida em sociedade, como exemplo, educação, saneamento básico, acesso à saúde de qualidade, lazer etc. devem ser discutidos pelo público visando uma tomada de decisão e consenso do que é melhor para a comunidade. Uma vez que o cidadão abre mão da sua liberdade e não participa de decisões públicas, está dando ao estado maior poder para decidir e regular suas necessidades e sua vida. O consumismo desenfreado, por exemplo, é um dos sintomas do capitalismo. Enquanto sistema econômico, o capitalismo produz necessidades que os sujeitos precisam satisfazer, e no final das contas, a busca por satisfação vira um ciclo vicioso que promove a manutenção do próprio sistema. O que não pode acontecer é que os interesses sistêmicos ligados a mecanismos de controle venham a impedir a discussão e a nublar a consciência dos sujeitos frente a situações/problemas de uma comunidade.

Existe, nas sociedades complexas atuais, entre o mundo da vida e o sistema, uma relação que Habermas chama de "colonização do mundo da vida". Essa colonização acontece na medida que, cada vez mais o mundo sistêmico invade o mundo da vida. Isso significa que, é crescente a transformação de relações espontâneas em relações de interesse e poder. $\mathrm{O}$ que era para ser espaço de cooperação e interação mútua e comunicativa entre os sujeitos, passa a ser espaço e relação de conflito, disputa e opressão. Em seguida, a citação mostra de que forma o agir comunicativo contribui para o impedimento dessa "colonização do mundo da vida".

A garantia da manutenção desse fundo de resistência à colonização não é assegurada por nenhum outro recurso que não a própria ação comunicativa entre os indivíduos, porém o destino final desse processo é incerto. A única garantia que a humanidade tem em relação ao futuro dessa resistência reside na sua própria necessidade social, historicamente produzida, de integridade moral e política, ou seja, estamos à mercê de nossa capacidade de definir formalmente nossa identidade social, coletiva, e nossa individualidade. Para tanto, dispomos de um único recurso: o agir comunicativo (MUHL, 2003, p. 103).

Portanto, a única forma de resistir a "colonização do mundo da vida" é defender uma cooperação ética nas relações sociais e viver de acordo com ela. Há uma necessidade de se viver em sociedade, assim como há uma necessidade do outro. Portanto, o importante é unir-se socialmente em prol de causas comuns, pois é somente a partir de um diálogo argumentativo, ético, cooperativo e consensual que a ideia de coletividade será instaurada.

Consciência social: racionalidade ética e senso de coletividade

Habermas defende uma racionalidade ética em detrimento de uma racionalidade instrumental. A racionalidade ética tem como pressuposto a verdade, a normatividade e visa um consenso. A consciência social só é possível por meio do diálogo, do estar junto 
com o outro, isto é, de uma integração social que afirma cada vez mais a identidade dos sujeitos. Nesse sentido, a citação a seguir mostra a importância da identidade do "eu" em relação com a comunidade, e qual a diferença entre a noção de identidade do sujeito para Marx e para Habermas

Argumentando que Marx teria enfatizado a construção do sujeito a partir do trabalho, das forças produtivas, minimizando o desenvolvimento do "eu", Habermas propõe que a institucionalização da identidade do sujeito, a autoconsciência- o processo de formação do espirito e da espécie- seja concebido como resultante de ambos os processos: do trabalho e da luta pelo reconhecimento (interação). Enfatizando o potencial emancipatório da esfera cultural, onde se dão os processos de interação, em detrimento da esfera do trabalho- regido pelas regras de uma racionalidade instrumental- Habermas aponta para a formação do sujeito, da identidade do "eu", como um processo de aquisição de uma competência interativa, que consistiria na capacidade de participar em sistemas de ação cada vez mais complexos, onde poderia questionar as "pretensões de validade" embutidas na linguagem institucionalizada, através da argumentação, e buscar o entendimento (consenso) sobre a validade das normas sociais (DELUIZ, 1995, p. 4).

$\mathrm{Na}$ teoria do Agir Comunicativo é fundamental reconhecer o outro. Como reconhecer o outro na sua diferença e, ao mesmo tempo, incluí-lo numa comunidade de direito segundo instituições justas? O tema do outro é desdobrado entre os conceitos de justiça e reconhecimento. Como reconhecer o outro na sua diferença e, ao mesmo tempo, incluí-lo numa comunidade de direito segundo instituições justas? Problematizase as dificuldades de estabelecer um direito formal, com uma abrangência internacional, que inclua e coordene as facticidades culturais, isto é, as diferenças regionais, étnicas e individuais.

Se a inclusão do outro é um desafio, é preciso tentar implementá-la conjugando sensibilidade à diferença e uma racionalidade que visa progressivamente um consenso crítico ampliado, a se confirmar na criação de instituições justas que se traduzem na forma de um Estado em permanente diálogo com a sociedade civil e seus mundos da vida correspondentes. (MELO, 2011b).

A facticidade (o que está dado como realidade concreta) deve buscar as condições de sua validade (a justificação racional que legitima uma norma para uma comunidade). Na sequência a citação apresenta a preocupação da racionalidade ética comunicativa em relação a vida prática dos sujeitos

Através da reciprocidade e da possibilidade de responsabilizar, o solo da ética é o da exigência de que o discurso/discussão resolva conflitos, por isso a ética do discurso é uma ética apropriada. Ela não é dogmática, seus princípios não são autoritários. Como ela depende de situações em que o discurso tenha valor e validade, s eu maior desafio é a inclusão de um número cada vez maior de pessoas educadas, responsáveis, participantes, a fim de que grupos, organizações, instituições, fóruns- realizem o princípio ético de uma racionalidade comunicativa, em que a validade provém da capacidade de argumentar com seriedade (ARAÚJO, 2009, p. 279).

A consciência social é o resultado de sujeitos engajados, participativos em todas as questões da comunidade, sejam questões educacionais, políticas ou sociais. Participar de assuntos públicos, isto é, que dizem respeito a todos, é contribuir efetivamente para a construção de uma realidade melhor, é estar consciente e atento a todos os mecanismos de controle, as formas de poder e aos discursos ideológicos.

Para Habermas, uma consciência social plenamente exercida e esclarecida implica uma comunidade ética constituída pluralisticamente através da ação comunicativa. Uma vez que falar é fazer, os contextos de fala são animados por uma pretensão de validade e busca de normatividade. Na concepção habermasiana, isto só é 
possível se superarmos a cisão entre liberalismo e comunitarismo, estabelecendo as bases de uma social democracia ou uma democracia deliberativa baseada no uso público da razão. Conforme Melo:

Pluralismo e democracia têm importâncias decisivas para a autocompreensão de
nossas sociedades modernas e de nossas orientações emancipatórias. Pois não há
espaço para a realização da autonomia se não atentamos aos limites de
universalismos etnocêntricos, às crescentes demandas por reconhecimento, à
conceitualização da cidadania sob condições multiculturais e sua relação com a
democracia etc. Uma concepção de democracia que possibilita um pluralismo não
apenas inevitável, mas desejável, tem de ser aquela mais sensível à
individualização das formas de vida autônoma e sua tradução política nas
mobilizações plurais por emancipação. O pluralismo social e cultural altera a
percepção da gramática dos conflitos sociais e dessubstancializa as lutas
emancipatórias na autonomia das formas de vida. Isso levou a teoria crítica
contemporânea a conceber uma concepção de uso público da razão capaz de
abarcar em si a multiplicidade das vozes de seus cidadãos e estabelecer bases
radicalmente democráticas de legitimação $(2011 \mathrm{~b}$, p. 201).

A luta por reconhecimento nos espaços democráticos atualiza a racionalidade comunicativa numa comunidade ética em processo. Toda deliberação pública implica discussão que, por sua vez, pressupõe uma implicação intersubjetiva. Uma ética do discurso demanda uma política deliberativa favorável à liberdade em conexão com as exigências da comunidade, mediada pela comunicação (HABERMAS, 2007a).

Assim, como nota Habermas, as sociedades complexas contemporâneas articulam as dimensões do sistema e do mundo da vida. Trata-se, então, de estabelecer a legitimidade das instituições através de uma prática comunicacional aberta e inclusiva que, pouco a pouco, permite estabelecer o consenso de comunidade sem neutralizar a pluralidade dos falantes. Eis o desafio de nossa época.

Considerações finais

Pensar o humano exige que o consideremos enquanto ser subjetivo, racional, concreto e que estabelece relações. O ser humano é linguagem e cultura. Enquanto ser de relação interage soçialmente a fim de se desenvolver junto do outro e se realizar enquanto indivíduo. É por meio da comunicação que o humano expressa suas necessidades e busca a resolução de conflitos. Os conflitos, por sua vez, nascem dos discursos ideológicos e alienantes que buscam manipular e coisificar o humano. Se de um lado, a realidade é instrumental e opressora, por outra via, ela pode ser discursiva, ética e plural. A defesa que se faz é que os indivíduos sejam responsáveis na comunidade. Tal responsabilidade implica uma consciência social esclarecida. Estar consciente, nesse sentido, significa compreender as manifestações do mundo sistêmico e engajar-se no mundo da vida de modo comprometido com a comunidade.

Os processos de alienação precisam ser compreendidos para que o sujeito se perceba como parte importante de uma sociedade, quando se pensa em resolução de problemas, escolhas e decisões que afetam a todos. A voz do indivíduo só pode ser ouvida por meio do discurso racional. Todavia, trata-se de uma racionalidade ética encarnada na ação comunicativa, conforme nos faz ver Habermas.

O diálogo aberto e responsável é o único caminho possível para se chegar a um consenso e a uma vida social cooperativa. Dessa forma, é somente através do Agir Comunicativo que os indivíduos podem resistir à instrumentalização das relações, aos discursos ideológicos e a alienação sócio-política.

A importância da filosofia habermasiana está em ter feito uma síntese crítica entre métodos diversos, debruçando-se sobre o problema crucial do funcionamento das sociedades atuais e da possibilidade de legitimação e emancipação no interior destas. A noção de razão comunicativa parece fecunda para compor uma crítica da alienação aliada ao exercício de emancipação na esfera pública. 


\section{REFERÊNCIAS}

ABRAHAM, B. Holocausto. São Paulo: WGCP, 1976, 160p.

ARAÚJO, L. I. Apel e Habermas: A ética do discurso. In: SGANZERLA, A. FALABRETTI, E. BOCCA, F. Ética em movimento: contribuições dos grandes mestres da Filosofia. São Paulo: Paulus, 2009. (272-281).

BRAGA, J.O. NETO, A.E. Trabalho alienado e a propriedade privada nos Manuscritos Econômico-Filosóficos. Revista eletrônica Arma da Crítica. n. 4 dez/2012. ISSN 19844735.

Disponível

em $<$ http://www.armadacritica.ufc.br/phocadownload/artigo3 20131.pdf $>$ Acesso em 06 de Setembro de 2015.

DELUIZ, N. Formação do sujeito e a questão democrática em Habermas. Boletim Técnico do Senac - v. 21, n. 1, jan./abr., 1995. Disponível em $<$ http://biblioteca.senac.br/fulltext/pdf/2101014021.pdf $>$ Acesso em 05 de Agosto de 2015.

DUTRA, D. V. Kant e Habermas: a reformulação discursiva da moral Kantiana. Porto Alegre: EDIPUCRS, 2002.

HABERMAS, J. (aut.); FREITAG, B.; ROUANET, S. P. (orgs.) Habermas: sociologia. São Paulo: Ática, 1990.

HABERMAS, J. Comentários à ética do discurso. Lisboa, PO: Instituto Piaget, 1991.

HABERMAS, J. O Discurso Filosófico da Modernidade. São Paulo: Martins Fontes, 2000.

HABERMAS, J. Consciência moral e agir comunicativo. Rio de Janeiro, RJ: Tempo Brasileiro, 2003.

HABERMAS, J. Pensamento Pós-Metafísico. Coimbra: Almedina, 2004.

HABERMAS, J. A inclusão do outro: estudos de teoria política. São Paulo: Loyola, 2007a.

HABERMAS, J. A Ética da Discussão e a Questão da Verdade. São Paulo: Martins Fontes, 2007b.

HABERMAS, J. Teoria do agir comunicativo: racionalidade da ação e racionalização social. São Paulo: Martins Fontes, 2012a.

HABERMAS, J. Teoria do agir comunicativo: sobre a crítica da razão funcionalista. São Paulo: Martins Fontes, 2012b.

HEGEL. G. W. F. Fenomenologia do espirito. Petrópolis: Vozes, 2002.

HENNIGFELD, J.; HEINZ, J. Filósofos da Atualidade. São Leopoldo: Unisinos, 2004.

MARX, K. Manuscritos econômico-fílosóficos e outros textos escolhidos. São Paulo: Nova Cultural, 1987.

MELO. R. O uso público da razão: Pluralismo e Democracia em Jurgen Habermas. São Paulo: Loyola, 2011 b.

MELO. R. Teoria crítica e os sentidos da emancipação. Cad. CRH vol.24 n.62 Salvador Maio/Agost. 2011a ISSN 0103-4979. Disponível em $<$ http://www.scielo.br/scielo.php?pid=S010349792011000200002\&script=sci arttext > Acesso em 06 de Setembro de 2015.

MUHL, E. H. Habermas e a educação: ação pedagógica como agir comunicativo. Passo Fundo: UPF, 2003.

TROMBLEY, S. Cinquenta Pensadores que Formaram o Mundo Moderno. Rio de Janeiro: LeYa, 2014.

VIEIRA. R. Z. A teoria crítica de Habermas frente à perspectiva onto-prática de Marx. Cadernos CEMARX-Centro de estudos Marxistas. UFCH-UNICAMP. n. 1, 2004. Disponível em $<$ http://www.ifch.unicamp.br/ojs/index.php/cemarx/article/view/1352/927> Acesso em 07 de Setembro de 2015. 